\title{
A RELAÇÃO ENTRE O DIREITO E A EDUCAÇÃO INCLUSIVA
}

\author{
THE RELATIONSHIP BETWEEN LAW AND INCLUSIVE EDUCATION
}

LA RELACIÓN ENTRE LA LEY Y LA EDUCACIÓN INCLUSIVA

\author{
Arthur Silva Araújo \\ Mestre em Educação e Professor - UNINTER. \\ Orcid: https://orcid.org/0000-0002-9905-6850. \\ E-mail: arthur_40@hotmail.com.br
}

\begin{abstract}
Ademir A. P. Mendes
Professor Titular Do Programa de Mestrado. Doutorado Profissional em Educação e Novas Tecnologias UNINTER.

Orcid: https://orcid.org/0000-0003-4929-9544.

E-mail: ademir.m@uninter.com
\end{abstract}

\author{
Suzana A. Galeazzi \\ Mestranda em Educação e Novas Tecnologias Centro Universitário Internacional (PPGENT/UNINTER). \\ Orcid: https://orcid.org/0000-0003-4444-6293. \\ E-mail: suzanagaleazzi@hotmail.com.
}

\begin{abstract}
RESUMO
O objeto deste estudo é o papel da Educação em Direitos Humanos, conforme a Declaração Universal dos Direitos Humanos (DUDH), especialmente no que diz respeito à inclusão de estudantes no ensino básico. $O$ objetivo geral da pesquisa é compreender os artigos da Constituição Federal de 1988, sobretudo, em relação ao teor do art. 26 da Declaração Universal dos Direitos Humanos, que trata da inclusão de estudantes na educação como um direito de todos. A metodologia desta pesquisa recorre às análises documental, descritiva e bibliográfica. Embora os resultados e as discussões mostrem avanços, também demonstram que a educação ainda não é inclusiva como detalha a lei. Encontram-se evidências de que a Lei da Pessoa com Deficiência, ao garantir a adaptação das atividades curriculares, culturais e teóricas, na escola, fortalece o trabalho pedagógico e amplia as diversidades educacionais.
\end{abstract}

Palavras-chave: Direitos do educando. Dever de educar. Política mundial da educação. Liberdade na escola e no ensino.

\section{ABSTRACT}

The object of this study is the role of Human Rights Education in Brazil, according to the Universal Declaration of Human Rights (UDHR), especially regarding the inclusion of students in basic education. The general objective of the research is to understand the articles of 1988's Brazilians Federal Constitution, particularly in relation to the content of article 26 of the Universal Declaration of Human Rights, which deals with the inclusion of students in education as a right for all. The methodology of this research resorts to documentary, descriptive, and bibliographic analysis. Although the results and the discussions show advances, they also demonstrate that education is not yet inclusive as detailed in the law. There is evidence that the Law of the Person with Disability, by guaranteeing the adaptation of curricular, cultural, and theoretical activities at school, strengthens the pedagogical work and expands educational diversities.

Keywords: Students' rights. Duty to educate. Global education policy. School and teaching freedom. 


\section{RESUMEN}

El objeto de este estudio es el rol de la Educación en Derechos Humanos según la Declaración Universal de Derechos Humanos (DUDH), especialmente en lo que a la inclusión de estudiantes en la educación básica se refiere. El objetivo general de la investigación es comprender los artículos de la Constitución Federal de 1988, sobre todo respecto a la orientación del artículo 26 de la Declaración Universal de los Derechos Humanos, que trata de la inclusión de los estudiantes en la educación como un derecho de todos. La metodología de esta investigación recurre al análisis documental, descriptivo y bibliográfico. Aunque los resultados y discusiones muestren adelantos, también demostraron que la educación aún no es inclusiva como se especifica en la ley. Se encontraron evidencias de que la Ley de Personas con Discapacidad, por el hecho de garantizar la adecuación de las actividades curriculares, culturales y teóricas en la escuela, fortalece el trabajo pedagógico y amplía las diversidades educativas.

Palabras-clave: Derechos del alumno. Deber de educar. Política mundial de educación. Libertad en la escuela y en la enseñanza.

\section{INTRODUÇÃO}

Este artigo desenvolve um estudo acerca da educação e dos direitos humanos, os quais, entre tantos outros constitucionalmente garantidos, afirma-se historicamente como categoria de direitos dos quais todos devem gozar, de forma permanente e global. A educação é um alicerces dos direitos referidos na Declaração Universal dos Direitos Humanos (DUDH).

São constantes os desafios enfrentados no mundo para a construção da cidadania, por meio de espaços de atuação que assegurem os direitos de todos os seres humanos. Assim, este trabalho objetiva compreender o papel dos artigos da Constituição de 1988 na Educação Inclusiva, bem como as relações que estabelecem, em especial, a respeito da inclusão de estudantes como um direito à educação de todos os brasileiros.

A metodologia utilizada foi a pesquisa bibliográfica enriquecida com algumas análises documentais, nas quais foi possível detalhar e observar a educação inclusiva e o direito à educação para todos.

Este estudo foi realizado para compor parte dos créditos do Mestrado Profissional em Educação e Novas Tecnologias da Uninter, na disciplina Educação em Direitos Humanos.

\section{Educação inclusiva: leis e desafios na educação brasileira}

A educação escolar promove o direito a um espaço primordial, fundante, principalmente diante das grandes transformações no mundo contemporâneo. Não é 
possível negar essa possibilidade à humanidade, posto que a educação básica passou a ser um princípio indispensável em textos legais mundialmente.

Segundo Bobbio (1992, p. 79-80)

a existência de um direito, independente do sentido forte ou fraco, necessita de um sistema normativo, a fim de entender-se tanto o mero fator exterior de um direito histórico ou vigente assim como o reconhecimento de um conjunto de normas como guia da própria ação, ou seja, a figura da obrigação.

Sendo assim, destaca-se a educação como indispensável às políticas que visam a participação de todos nos espaços de cidadania plena, mediada pelos valores que a educação atinge, de instruções e sentimentos humanos, nos quais os direitos humanos, em relação à Educação, pressupõem continuar a trabalhar juntos para desenvolver e cultivar, nas futuras gerações, a cidadania plena de direitos e deveres, constituídos historicamente no intuito de promover liberdade, segurança e paz em todas as nações.

A educação é compreendida como "um lado em que a transformação do homem opera sobre o meio, e por outro, os resultados dessa transformação" (SAVIANI, 1991, p. 40). Contudo, o educar perpassa o sentido de humanizar, uma afirmação de que a natureza humana não é dada.

O trabalho educativo é o ato de produzir, direta e intencionalmente, em cada indivíduo, a humanidade histórica e coletivamente constituída pelo conjunto dos homens (SAVIANI, 1991, p. 21). Isto posto, para o trabalho educativo, "incluir é o mesmo que compreender, que por sua vez, quer dizer entender, alcançar com a inteligência" (FERREIRA, 2010, p. 93).

Ao destacar a educação inclusiva, este trabalho aborda a questão das crianças com necessidades especiais, as quais devem ter garantia de assistência no cotidiano escolar, de modo que possam superar suas dificuldades e desenvolver suas potencialidades, com respeito ao percurso de aprendizagem individual.

É dever do Estado garantir atendimento especializado às pessoas com necessidades especiais, conforme lei vigente, principalmente quando o assunto é educação. Como informa o art. 2, da lei n. ${ }^{\circ} 7.853 / 89^{1}$ :

Poder Público e seus órgãos cabem assegurar às pessoas portadoras de deficiência o pleno exercício de seus direitos básicos, inclusive dos direitos à educação, à saúde, ao trabalho, ao lazer, à previdência social, ao amparo à infância

${ }^{1}$ Disponível em: http://www.planalto.gov.br/ccivil_03/leis/l7853.htm. Acesso em: 4 jun. 2021. 
e à maternidade, e de outros que, decorrentes da Constituição e das leis, propiciem seu bem-estar pessoal, social e econômico.

Portanto, é preciso observar que, segundo a lei, no tocante à matrícula e à aceitação, qualquer instituição de ensino que recusá-las a estudantes com necessidades especiais, no regime de ensino educacional, poderá responder pelos crimes mencionados no art. 8 , da lei $.^{\circ} 7.853 / 89$ :

constitui crime punível com reclusão de 1 (um) a 4 (quatro) anos, e multa: I recusar, suspender, procrastinar, cancelar ou fazer cessar, sem justa causa, a inscrição de aluno em estabelecimento de ensino de qualquer curso ou grau, público ou privado, por motivos derivados da deficiência que porta; II - obstar, sem justa causa, o acesso de alguém a qualquer cargo público, por motivos derivados de sua deficiência; III - negar, sem justa causa, a alguém, por motivos derivados de sua deficiência, emprego ou trabalho; IV - recusar, retardar ou dificultar internação ou deixar de prestar assistência médico-hospitalar e ambulatorial, quando possível, à pessoa portadora de deficiência; $V$ - deixar de cumprir, retardar ou frustrar, sem justo motivo, a execução de ordem judicial expedida na ação civil a que alude esta Lei; VI - recusar, retardar ou omitir dados técnicos indispensáveis à propositura da ação civil objeto desta Lei, quando requisitados pelo Ministério Público.

Não são poucos os documentos que trazem a idealização da garantia de direito à educação e, principalmente, à educação inclusiva. Sendo assim, indaga-se: o tratamento igualitário é oferecido, de fato? A qualidade da educação é garantida a todos?

Segundo o legado da Constituição de 1988, o processo de inclusão na educação deverá ocorrer como um "bem de todos, sem preconceito de origem, raça, sexo, cor, idade, e quaisquer outras formas de discriminação".

A inclusão escolar está diretamente relacionada aos processos político, social, cultural e pedagógico da escola. Sendo assim, torna-se possível a interação entre crianças com necessidades especiais e sem necessidades especiais, em convivência no ambiente escolar, aprendendo e respeitando suas diferenças (LIMA, 2006).

Em vista das dificuldades dos professores no atendimento, "é essencial que os professores reconheçam sua própria importância no processo de inclusão, pois a eles cabe planejar e implementar intervenções pedagógicas que deem sustentação para o desenvolvimento das crianças" (LIMA, 2006, p. 123).

No art. 26, da Declaração Universal dos Direitos Humanos, mais especificamente sobre o Direito à Educação, encontra-se o seguinte:

1. Todo ser humano tem direito à instrução. A instrução será gratuita, pelo menos nos graus elementares e fundamentais. A instrução elementar será obrigatória. A 
instrução técnico-profissional será acessível a todos, bem como a instrução superior, está baseada no mérito.

2. A instrução será orientada no sentido do pleno desenvolvimento da personalidade humana e do fortalecimento do respeito pelos direitos do ser humano e pelas liberdades fundamentais. A instrução promoverá a compreensão, a tolerância e a amizade entre todas as nações e grupos raciais ou religiosos e coadjuvará as atividades das Nações Unidas em prol da manutenção da paz.

3. Os pais têm prioridade de direito na escolha do gênero de instrução que será ministrada a seus filhos (ONU, 1948, [n.p.]).

A Declaração Universal dos Direitos Humanos (DUDH) foi adotada no ano de 1948, no dia 10 de dezembro. Esta mostra o que foi possível alcançar a partir das leis instituídas, e o percurso a seguir em honra de todos aqueles que contribuíram com novas inspirações.

O art. 26 afirma que "a educação será orientada no sentido do pleno desenvolvimento da personalidade humana". Assim sendo, a educação se destaca como uma das mais importantes ferramentas de garantia de direitos, posto que todos têm o direito à educação. A educação gratuita, pelo menos nas aulas elementares (iniciais) e fundamentais, é obrigatória em todos os países.

A educação na área técnico-profissional é acessível e aberta a todos, cada qual com o mérito e os conhecimentos necessários, por meio de formação profissional, de modo que seja possível ascender a instruções superiores.

A educação é um processo que leva o pensamento a uma socialização permanente, praticada nos diversos espaços de convivência, para que o indivíduo consiga se adequar aos grupos sociais. Ou seja, é uma união entre os processos de ensinar e de aprender, de forma que contemple os ajustes e as adaptações da educação aos meios disponíveis.

A Constituição de 1988 assevera, em seu art. 205, que a

educação, direito de todos e dever do Estado e da família, será promovida e incentivada com a colaboração da sociedade, visando ao pleno desenvolvimento da pessoa, seu preparo para o exercício da cidadania e sua qualificação para o trabalho (BRASIL, 1988, p. 121).

Diante dessa demanda, cabe ao profissional da educação, ao pensar o planejamento de aula, contemplar a adaptação de atividades para todas as crianças, tendo em vista potencialidades e dificuldades de cada uma, independentemente se caracterizada ou não como estudante de inclusão.

A inclusão escolar é por vezes mal compreendida, principalmente no seu apelo a mudanças nas escolas regulares e especiais. Sem essas mudanças, não se pode garantir nas escolas condições para recebimento, indistintamente, de todos os alunos, oferecendo-lhes 
oportunidade de prosseguir em seus estudos, segundo a capacidade de cada um, sem discriminações nem espaços segregados (MANTOAN, 2006).

A prática pedagógica na educação se direciona à formação humanística e social. Neste contexto, afirma-se que todos os estudantes, incluindo os com necessidades especiais, podem participar de tudo e com todos, desenvolvendo-se em meio aos colegas de classe sem nenhuma distinção. Ou seja, cada vez mais é necessário o investimento na formação pedagógica para que os profissionais da educação se aprimorarem e estejam seguros para construir um planejamento adaptável a todos.

Sendo a escola o lugar onde as múltiplas relações advêm de aspectos sociais, humanos e culturais, e considerando que todos são iguais perante a lei, é inevitável afirmar também o contrário: cada um possui uma história e uma identidade, que os torna seres únicos.

Assim, segundo Mantoan (2004, p. 7-8):

há diferenças e há igualdades, e nem tudo deve ser igual nem tudo deve ser diferente, $[. .$.$] é preciso que tenhamos o direito de ser diferente quando a$ igualdade nos descaracteriza e o direito de ser iguais quando a diferença nos inferioriza.

O processo de inclusão no âmbito educacional ainda é muito recente e passa por aprimoramento a cada situação. Quando se compreende que a escola é inclusiva, para todos, e atende ao coletivo, bem como à individualidade do estudante, pode-se avançar não somente na educação inclusiva, mas em todo o enredo da educação, de maneira que se efetive o princípio do direito a esta.

Ao debater a prática pedagógica da educação inclusiva é importante colocar em pauta a lei vigente que preconiza o cotidiano escolar. Assim,

a educação especial é uma modalidade de ensino que perpassa todos os níveis, etapas e modalidades, realiza o atendimento educacional especializado, disponibiliza os recursos e serviços e orienta quanto a sua utilização no processo de ensino e aprendizagem nas turmas comuns do ensino regular (BRASIL, 2008, p. 7).

O processo educativo apresenta aprimoramentos vinculados às leis vigentes, como se verifica nos incisos IX e XV, do art. 28 , da Lei Brasileira de Inclusão da Pessoa com Deficiência, Capítulo IV - Do Direito à Educação: “IX - Adoção de medidas de apoio que favoreçam o desenvolvimento dos aspectos linguísticos, culturais, vocacionais e profissionais, levando-se em conta o talento, a criatividade, as habilidades e os interesses 
do estudante com deficiência"; "XV - Acesso da pessoa com deficiência, em igualdade de condições, a jogos e a atividades recreativas, esportivas e de lazer, no sistema escolar".

Depreende-se que nenhuma escola pode dizer "não" ao estudante com necessidades especiais, pois, a lei defende condições igualitárias a todos, as quais requerem adoção de medidas de apoio que promovam o mesmo desenvolvimento de habilidades e diversas capacidades na educação em geral: “o olhar do professor deve ser único para cada estudante, porque cada estudante é único" (PIEKARSKI, 2014, p. 116).

Ao contrário de pensar no estudante como a origem de um problema, exigindo-se dele um ajustamento aos padrões de aprendizagem dos demais, "coloca-se para os sistemas de ensino e para as escolas o desafio de construir coletivamente as condições para atender bem à diversidade de seus alunos" (BRASIL, 2001, p. 6).

Com adaptações na educação inclusiva, busca-se constituir uma educação de qualidade para todos, equanimemente, respeitando o percurso individual do estudante diante dos desafios de superar suas dificuldades e desenvolver suas potencialidades, considerando também o protagonismo dos estudantes que se manifestam por diversas maneiras.

Sendo assim,

para trabalhar a socialização na perspectiva de desenvolvimento de uma nova cultura que tenha o ser humano e sua dignidade como foco e que prime pela construção de uma sociedade inclusiva, é necessário abrir o campo perceptivo do educador e reeducar essa percepção de forma a despertar o interesse e a crítica diante dos acontecimentos (HORTA, 2000, p. 129-130).

As adaptações curriculares na educação inclusiva ocorrem mediante

o atendimento educacional especializado que disponibiliza programas de enriquecimento curricular, o ensino de linguagens e códigos específicos de comunicação e sinalização, ajudas técnicas e tecnologia assistiva, dentre outros. Ao longo de todo processo de escolarização, esse atendimento deve estar articulado com a proposta pedagógica do ensino comum (BRASIL, 2008, p. 16).

A maior dificuldade dos profissionais da educação está relacionada à ausência de disciplinas e práticas pedagógicas que contemplem a educação inclusiva na grade curricular dos cursos superiores. Portanto, a vários educadores faltam conhecimentos teóricos e práticos sobre estudantes com necessidades especiais.

Como informa a Lei Brasileira de Inclusão da Pessoa com Deficiência de n. ${ }^{\circ}$ 13.146: “assegurar e promover, em condições de igualdade, o exercício dos direitos e das 
liberdades fundamentais por pessoa com deficiência, visando à sua inclusão social e cidadania".

Por conta disso, a escola, que já atende à educação inclusiva, incentiva os professores a participarem de processos formativos complementares que os capacitem a desenvolver adequações metodológicas para atendimento de todos os estudantes, ressaltando a especificidade da educação inclusiva.

De acordo com o art. 28: “Incumbe ao poder público assegurar, criar, desenvolver, implementar, incentivar, acompanhar e avaliar". Desta forma, asseguram-se os incisos IX e $\mathrm{XV}$, os quais preconizam o desenvolvimento do discente com necessidades especiais e a igualdade de condições perante a lei.

Assim, devem-se empreender transformações necessárias na educação para que a inclusão se torne realidade nas escolas brasileiras e passe a ser uma tarefa de todos, de modo que tenham possibilidade de atuar conforme seus desejos e anseios.

De acordo com o exposto pela Unesco (1994), sobre a Declaração de Salamanca:

as escolas integradoras constituem um meio favorável à construção da igualdade de oportunidades da completa participação; mas, para ter êxito, requerem um esforço comum, não só dos professores e do pessoal restante da escola, mas também dos colegas, pais, famílias e voluntários. A reforma das instituições sociais não só é uma tarefa técnica, mas também depende, antes de tudo, da convicção, do compromisso e da boa vontade de todos os indivíduos que integram a sociedade (UNESCO, 2004, p. 14).

Nesta visão, Freire (1999, p. 25) declara que "ensinar não é transmitir conhecimento, mas criar as possibilidades para sua produção ou a sua construção", fazendo uma educação flexível e dinâmica a qual possibilite ao sujeito à interação com a sociedade.

Ressalta-se que a escola é um ambiente vivo, dotada de amplas possibilidades, da qual fazem parte os estudantes com necessidades especiais, sendo necessário o investimento público de recursos materiais, físicos e humanos para garantir a qualidade de ensino.

Glat e Nogueira (2003, p. 1) destacam que "não basta que uma proposta se torne lei para que a mesma seja imediatamente aplicada. Inúmeras são as barreiras que impedem que a política de inclusão se torne realidade na prática cotidiana de nossas escolas”.

Já afirmava Mandela que "a educação é a arma mais poderosa que você pode usar para mudar o mundo" (MANDELA et al., 2003, [n.p.]). Portanto, deve-se viabilizar o percurso por meio do qual é possível levar a educação básica de forma gratuita e universal 
a todos, reconhecimento fundamental para o desenvolvimento das nações, sem se escusar os direitos das crianças, conforme o Estatuto da Criança e do Adolescente.

\section{CONSIDERAÇÕES FINAIS}

As instituições de ensino, quando se trata de educação inclusiva, estão em fase de adaptações significativas. Conforme a urgência da situação, procuram desenvolver suas atividades culturais e teóricas para fortalecer o entendimento e a união da sociedade educacional nas suas diversidades.

Destaca-se a busca por uma aprendizagem mais humana, posto que o grande desafio da inclusão é tornar o processo de ensino-aprendizagem mais adaptativo. O que toda criança inserida no universo escolar almeja é ter suas necessidades, anseios, descobertas, potencialidades, projeções para o futuro, entre outros, atendidos.

Nessa perspectiva, entende-se que a busca de qualidade de vida requer principalmente qualidade na educação, o que não se faz isoladamente, mas por meio de diferentes relações, dentre elas, a formação constante dos profissionais da educação.

Por fim, este artigo destaca o nível de participação e sensibilização promovidas pela educação, e como a ampliação desse universo pode favorecer o crescimento da sociedade no sentido garantir equidade. Portanto, a educação é a transformação do nosso senso crítico em relação ao exercício da cidadania.

\section{REFERÊNCIAS}

BOBBIO, N. A era dos direitos. Rio de Janeiro: Campus 1992.

BRASIL. Constituição da República Federativa do Brasil de 1988. Brasília, DF: Presidência da República, 2021. Disponível em: http://www.planalto.gov.br/ccivil_03/constituicao/constituicao.htm. Acesso em: 4 jun. 2021.

BRASIL. Ministério da Educação. Política Nacional de Educação Especial. Brasília: Secretaria de Educação Especial, 2008.

BRASIL. Ministério da Educação. Secretaria de Educação Especial. Diretrizes nacionais para a educação especial na educação básica. Brasília, DF: MEC, 2001. Disponível em: http://portal.mec.gov.br/seesp/arquivos/pdf/diretrizes.pdf. Acesso em: 4 jun. 2021. 
BRASIL. Política nacional de educação especial na perspectiva da educação inclusiva. Brasília, 2008. Disponível em: http://portal.mec.gov.br/arquivos/pdf/politicaeducespecial.pdf. Acesso em: 4 jun. 2021.

FERREIRA, C. A. Vivências de integração curricular na metodologia de trabalho de projecto. Revista Galego-Portuguesa de Psicoloxía e Educación, v. 18, n. 1, 2010. p. 91-105.

FREIRE, Paulo. Educação como prática da Liberdade. 23. ed. Rio de Janeiro: Paz e Terra, 1999.

GALVÃO, M. C. B. O levantamento bibliográfico e a pesquisa científica. In: FRANCO, L. J.; PASSOS, A. D. C. (Org.). Fundamentos de epidemiologia. 2. ed. São Paulo: Manole, 2010.

GERHARDT, T. E.; SILVEIRA, D. T. Métodos de pesquisa. 1. ed. Porto Alegre: Editora da UFRGS, 2009. Disponível em: http://www.ufrgs.br/cursopgdr/downloadsSerie/derado05.pdf . Acesso em: 4 jun. 2021.

GLAT, R.; NOGUEIRA, M. L. L. Políticas educacionais e a formação de professores para a educação inclusiva no Brasil. Revista Integração, Brasília, v. 14, n. 24, jun. 2003. p. 134-141.

GOFFREDO, Vera Lúcia Flor Sénéchal. Educação: direito de todos os brasileiros. In: SALTO PARA O FUTURO. Educação especial: tendências atuais. Brasília: Ministério da Educação, SEED, 1999.

HORTA, Maria del Mar. Educar em direitos humanos: compromisso com a vida. In: CANDAU, Vera; SACAVINO, Susana. Educar em direitos humanos. Rio de Janeiro: D\&P, 2000.

LIMA, Priscila Augusta, 1957. Educação inclusiva e igualdade social. São Paulo: Avercampo, 2006.

MANDELA, N. Iluminando seu caminho para um futuro melhor. Discurso no lançamento da Mindset network, 2003. Disponível: https://britto.com.br/a-educacao-e-a-arma-maispoderosa-que-voce-pode-usar-para-mudar-o-mundo/. Acesso em: 4 jun. 2021.

MANTOAN, M. T. E. Igualdade e diferenças na escola: como andar no fio da navalha. In: MANTOAN, Maria Teresa Eglér; PRIETO, Rosângela Gavioli. Inclusão escolar: pontos e contrapontos. São Paulo: Summus, 2006. p. 23.

MANTOAN, M. T. E. O direito de ser, sendo diferente, na escola. Revista CEJ, Brasília, v. 8, n. 26, jul./set. 2004. p. 36-44. Disponível em: http://www.cjf.jus.br/ojs2/index.php/revcej/article/view/622. Acesso em: 13 abr. 2021.

ONU. Assembleia Geral das Nações Unidas. Declaração Universal dos Direitos Humanos, Viena, 1948. Disponível em: https://www.unicef.org/brazil/declaracao-universal-dosdireitos-humanos. Acesso em 4 jun. 2021. 
PIEKARSKI, Teresa Cristina Trizzolini. A aprendizagem musical do estudante com deficiência intelectual em contexto de inclusão. Dissertação (Mestrado em Comunicação)Universidade Federal do Paraná, Curitiba, 2014. Disponível em: https://acervodigital.ufpr.br/handle/1884/45440. Acesso em: 4 jun. 2021.

SAVIANI, D. Educação: do senso comum a consciência filosófica. São Paulo: Autores Associados, 1991.

UNESCO. Declaração de Salamanca e linha de ação sobre necessidades educativas especiais. Brasília: CORDE, 1994.

Recebido em: 18/05/2021

Parecer em: 25/05/2021 Aprovado em: 21/06/2021 